\title{
A Support Programme for Caregivers of Children with Heart Disease in Rural Namibia
}

\author{
Kristofina Amakali*, Louis F. Small \\ School of Nursing and Public Health, University of Namibia (UNAM), Windhoek, Namibia \\ Email: kamakali@unam.na
}

Received August 2014

\section{Abstract}

The majority of children suffering from heart disease in Namibia receive treatment as outpatients, with their caregivers taking responsibility for their continuing care. To provide the care required by these children, the caregiver has to remain vigilant. Many of these children live in rural areas and their caregivers may have only a limited educational background, as well as limited financial resources, as they depend on subsistence agriculture for a living. The development of the support programme discussed in this article originated from the results of a qualitative, exploratory, phenomenological study that addressed the issue of how these caregivers managed this responsibility. The findings of this study revealed that the caregivers generally had poor coping experiences. Subsequently, these findings formed the basis for the proposal about a support programme for the rural caregivers of children with heart disease in Namibia. As part of the study, interventions for home-based health care were developed, implemented and evaluated in order to facilitate the caregiver's coping with the demands of home care. The findings of an outcomes evaluation indicated that the caregivers' knowledge of the child's condition, as well as the skills for providing care at home and the information about community-based resources that could provide them with support to cope, increased. If the programme were to be extended to other families in similar contexts, the programme interventions could make a difference in terms of their coping with the demands of care. This paper describes the implementation process involved in a home-based health care programme intervention of the study, and the subsequent outcomes of the programme evaluation.

\section{Keywords}

Heart Disease, Home-Based Health Care, Coping, Interventions, Implementation, Evaluation, Outcomes

\section{Background}

Heart disease contributes to about $10 \%$ of all paediatric admissions to healthcare facilities in Namibia. Congeni-

${ }^{*}$ Corresponding author. 
tal heart defects and rheumatic heart disease account for $60 \%$ and $40 \%$ respectively of these diseases. Moreover, congenital heart defects account for $9 \%$ of neonatal deaths in health facilities in Namibia. At the time of this study, there were about 500 children under the age of 18 who were in need of heart surgery [1].

The majority of these children receive treatment as outpatients and their caregivers have to provide palliative care for them at home. To provide the required care for a child with a heart disease requires vigilance on the part of the caregivers. This presupposes that caregivers have the necessary knowledge, skills and access to support systems for them to be able to cope with the demands that caring for these children requires [2] [3].

Nevertheless, this assumption is not true for the majority of cases in Namibia. Many of these children live in rural areas and their caregivers have low levels of education and depend on subsistence agriculture for a living. Therefore, a qualitative, descriptive naturalistic study was conducted to assess rural caregivers' experiences of caring for a child with heart disease at home. The findings revealed that caregivers experience challenged emotions related to the children's diagnosis. They also experience disruptive social functioning and social relations because of the demands of providing care for such children at home. Lack of support from the family and other societal organisations also hinders their coping with the demands of care. While the findings revealed poor coping with the demands of caring, the children's poor coping with the burden of the disease was found to compound the demands of caring made on the caregivers [4]. Subsequently, in line with the situational analysis and the subsequent findings of the study, a home-based health care programme of multi-component interventions was developed. The programme interventions were invented as an interface to mitigate the negative experiences and enable caregivers to provide appropriate home care that would facilitate positive health outcomes for the children. The implementation and the outcome evaluation of the programme interventions were completed in phase three of the study [4].

\section{Purpose of the Study}

The purpose of the study was to explore the rural caregivers' experiences of caring for a child with a heart disease, interpret the way in which the caregivers cope with the situation at home and identify the need for assistance. Therefore, the purpose of this article is to describe the implementation and evaluation of a support programme that was developed on the basis of the experiences of caregivers of children with heart disease in rural Namibia.

\section{Conceptual Framework}

A naturalistic, constructivist, interpretive and paradigmatic approach was adopted in the development and implementation of the support programme [5]. The conclusions on the findings of the outcome evaluation were based on what the participants regarded as their experiences of the programme interventions and their perceptions that the programme interventions had rendered the care of a child with a heart disease bearable for them [4]. The context in which their experiences occurred and which can influence their experiences of the programme intervention was also considered [5] [6]. In addition, the framework of the "transactional model of stress and coping" was applied to predict the way the caregivers and the children would appraise the benefits derived from the programme interventions in terms of caring for a child at home [5] [7].

\section{Study Design and Methods}

The development of the support programme was the final phase of an original study conducted by the author [4]. In the first phase of the original study, the researcher made use of a qualitative, descriptive, contextual and naturalistic study to describe the caregivers' experiences of caring for a child with heart disease, as well as children's experiences of living with a heart disease [6]. The target population for the study comprised all the caregivers of children with heart disease living in the rural areas of Namibia. From the findings, a multi-component homebased health care programme in support of caregivers was subsequently conceptualised according to Dickoff et al.'s (1968) [8] survey list.

\section{The Support Programme}

The interventions for this proposed home-based health care programme were developed by the researcher as an agent for the caregivers, who were to be regarded as the recipients of the programme. These interventions which 
were derived from the findings of the author's original study [4], focused on the facilitation of emotional coping, the mobilisation of social support for the caregivers, supportive family dynamics and the facilitation of an optimal functional status for the children with heart disease [7] [9]-[11]. The programme interventions were grouped and organised as three objectives. These three objectives were formulated in the original study with the aim of addressing the main findings, which had been categorised as three themes; thus, an objective for each theme.

Table 1 provides an outline of the programme.

The programme implementation, which will be discussed next, occurred during 2012.

\section{Ethical Considerations}

Formal ethical clearance for the main study, of which this support programme formed one phase, was obtained from the Postgraduate and Research Committee of the University of Namibia. The caregivers gave their informed consent for this phase verbally before commencing the implementation and evaluation of the programme activities [12], and participation was voluntary. The purpose of the interventions and their evaluation were explained prior to commencing the programme. Possible benefits that participation in the programme might bring were explained and the participants' expectations were dealt with.

\section{Programme Implementation}

The programme was implemented by the researcher in two rural households with children with heart disease. The two households were purposefully selected from the five households that featured in the researcher's originnal study.

Each participant received a programme schedule with a list of activities to be covered. They were also given a notebook and a pen to record any information that they deemed worth noting for future reference. The concept of experiential learning, which includes among other things both active participation, as well as concrete experience were applied in order to maximise the participants' learning [13]-[15]. A full day was allocated for implementing the interventions in each of the two households. These programme interventions were implemented in three sessions in each household, with each session lasting just over an hour. For this purpose, the participants were provided with information about simplified pathophysiology of heart disease and caring principles.

\subsection{Session One}

This session focused on interventions to facilitate emotion-focused coping. The caregivers were given, among other aspects, bereavement counselling to help them come to terms with either the fact that the child's illness was life long or with a poor prognosis. This activity included a discussion intended to promote understanding of the potential treatment outcomes of the child's diagnosis. The discussion provided a sympathetic clarification of what is meant by symptomatic treatment, and palliative concepts were introduced [16] [17].

Table 1. The components of a home-based health care programme.

\begin{tabular}{|c|c|c|}
\hline $\begin{array}{l}\text { Original study finding } \\
\text { presented as a theme }\end{array}$ & Objectives & Interventions \\
\hline $\begin{array}{l}\text { The caregivers and the children } \\
\text { experience challenging emotions }\end{array}$ & $\begin{array}{l}\text { Facilitation of emotion-focused coping } \\
\text { for the caregivers and the children }\end{array}$ & $\begin{array}{l}\text { Bereavement counselling venting, } \\
\text { disengagement, optimism, } \\
\text { acceptance, self-re-evaluation, use of religion } \\
\text { Self-efficacy }\end{array}$ \\
\hline $\begin{array}{l}\text { The caregivers experience disruptive } \\
\text { social functioning, social isolation, } \\
\text { and lack of support from the } \\
\text { family and social systems }\end{array}$ & $\begin{array}{l}\text { Facilitation of social support } \\
\text { mobilisation for the caregivers }\end{array}$ & $\begin{array}{c}\text { Supportive family dynamics. } \\
\text { Seeking of appropriate information about } \\
\text { the child's illness and social support } \\
\text { Socialisation }\end{array}$ \\
\hline $\begin{array}{l}\text { The children experience } \\
\text { decreased vitality }\end{array}$ & $\begin{array}{l}\text { Facilitation of optimal } \\
\text { functional status for the children }\end{array}$ & $\begin{array}{c}\text { Counselling of the children. } \\
\text { Cardiac diet and nutrition } \\
\text { Management of the child's weight } \\
\text { Activity tolerance } \\
\text { Symptomatic care for the child } \\
\text { Compliance with medication schedules }\end{array}$ \\
\hline
\end{tabular}


Mastering of self-efficacy was demonstrated with regard to listening with sympathy and providing care with respect, dignity and a non-judgmental attitude toward the child [18]. The use of religion was also discussed with the participants. In this regard, the participants were encouraged to use their religion as a foundation from which to derive positive meanings relating to the challenges of caring for their children [7].

\subsection{Session Two}

Session two focused on the discussion of supportive family dynamics and the mobilisation of social support for the caregivers. In this regard, the inclusion of all family members who were eligible to provide care for the child concerned in order to provide respite for the primary caregivers was encouraged. Ways in which appropriate information about the child's care could be obtained from health care workers was explained. The importance of social support and the socialisation of caregivers was also stressed [19] [20].

\subsection{Session Three}

Session three focused on interventions to facilitate optimal functional status for children with heart disease. The children were counselled in order to help them to construct self-directed solutions in respect of experiences of the symptoms of heart disease [21]. In addition, the diet for a child with a heart disease was discussed. In this regard, caregivers were shown how to prepare the food for the child's diet using foodstuffs that were available in the household. Nutrition, weight management and activity tolerance were discussed. Symptomatic care for the child and compliance with the medication schedule were also addressed in this section [9]. The participants were given feedback on their performance relating to these skill sand, when necessary, they were encouraged to improve [22]. The participants reflected on how they could apply the insights gained from the learning experiences to help them to cope with the demands of providing care for their children at home [23]. Table 1 displays the components of the home-based health care programme that was implemented.

\section{Programme Evaluation}

The programme was subsequently evaluated four months after its implementation. As the literature proposes, the purpose of such an outcomes evaluation is to ascertain whether the programme interventions have empowered the caregivers with the knowledge and skills they needed in order to cope with the demands of providing appropriate home care for their children [19] [24]-[26]. The specific objectives for the programme evaluation were threefold. The first objective was to evaluate the participants' (caregivers and the children) knowledge of aspects of emotional coping. The second objective was to evaluate the caregivers' knowledge and skills relating to the symptomatic care for the child and their ability to identify and use the social network. The third objective focused on evaluating the children's knowledge about their disease and self-care.

\subsection{Methods of Programme Outcomes Evaluation}

During the qualitative outcomes evaluation, conducted four months after the implementation of programme interventions, data were collected during interviews, and from the written testimonials of the participants' experiences of the programme interventions. These methods were used as they were most likely to secure the required information from the participants, taking into account the capabilities and the understanding of the participants. During the interviews, open-ended questions, as displayed below, were posed to give the participants the opportunity to describe their experiences of the programme interventions.

What did you learn from the programme interventions?

What was difficult for you in the programme interventions?

What could be improved in the programme interventions?

The data analyses were analysed according to the Tesch's qualitative data analysis method [27]. Codes were allocated to the main ideas and the findings were organised as themes.

\subsection{The Results from the Programme Evaluation: Presented as Themes}

Four themes emerged from the evaluation of the programme.

Theme one: Positive feedback on acquiring knowledge and skills;

Theme two: Feelings of acquiring an inner strength; 
Theme three: The realisation of family being a source of strength;

Theme four: The realisation of the community as a source of support.

\subsubsection{Theme One: Positive Feedback on Acquiring Knowledge and Skills}

Both the caregivers and the children learnt about the child's illness and the care required by the child. In this regard, the caregivers asserted that both they and the children had gained knowledge about the child's condition. Caregivers indicated that they were able to carry out the instrumental care tasks for their children. The following quotes from the participants are testimony to this.

"I have learnt a lot from the explanation about the child's illness and treatment. I have also learnt about those aspects of care for the child to prevent the child from getting sick, like how to protect the child from cold, not to get sick."

"The child (with heart disease) should eat less or no oil/fat and more of brown bread."

Furthermore, and in concurrence with the findings of other studies [28], the caregivers also indicated that, as a result of counselling interventions, the children were also demonstrating the ability to practise self-care management in response to their symptoms. This claim is evidenced from the following quotes by the caregiver:

"By now he knows that if he gets tired, he has to rest. He knows that he does not have to get cold. He always puts on his jersey every morning. He knows he has to wash with warm water. Therefore he puts his water in the sun to warm before bathing."

\subsubsection{Theme Two: Feelings of Acquiring an Inner Strength}

Theme two related to the fact that the caregivers believed that they had developed inner strength and determination to provide homecare for the child with heart disease, as evidenced by the testimony from one of the caregiver participants: "Your explanation about the waiting time for treatment also put me at ease." The interaction with the researcher was considered worthwhile and, as such, it added to the feeling of inner strength experienced by the caregivers.

"Sharing information with a health care provider also encourages one to have faith and wait for the child's treatment with confidence."

\subsubsection{Theme Three: The Realisation of the Family Being a Source of Strength}

Theme three refers to the perception that the family, and the family dynamics, could contribute significantly to caring for a child with heart disease at home. Additionally, and in accordance the findings from other studies [29], the caregivers reported that the programme interventions enhanced cohesion among the family members as regards the care for a child with heart disease. Therefore, the caregivers reported that they were then able to share the responsibilities of caring for the child, as can be verified from some of the quotes by one of the participants in this regard:

"We help each other at the family level to allow the focal caregiver to socialise."

\subsubsection{Theme Four: The Realisation of the Community as Source of Support}

In addition, the family could utilise community resources to help them cope with the demands of care at home. Furthermore, the caregivers reported that they were better of informed about seeking appropriate social support. In this regard, the caregivers indicated that they made use of local religious support and they participated in local community development initiatives as sources of emotional coping. The interaction with the researcher, who could be regarded as a community member, was considered worthwhile. As a result, caregivers voiced the need for more such opportunities. The following quotes, among many, bear testimony to this:

"The information is good. However it needs repetition, until one is thoroughly knowledgeable about all the aspects that you tough us."

"The other problem is that there is no continuous support by health care providers, in a form of a visit you paid to us."

"There is a need for a visit by a health care provider on a regular base to assess the child's condition, at least two (2 times) a year."

\section{Discussion}

The caregivers indicated that the implementation of the programme had rendered the management of their chil- 
dren with heart disease at home bearable. The caregivers demonstrated an increase in the knowledge and skills necessary to carry out instrumental tasks of caring for a child with a heart disease. They also gained inner strength and discovered possible resources available within their families and their communities.

Through the discussions, the interchange of ideas and the concrete experiences, the caregivers acknowledged that they had learnt new knowledge and values. These included successful at tempts at problem solving and active experimentation with instrumental tasks such as practising empathy towards the children. Another valuable lesson they had learnt from the programme was the preparation of the child's diet from locally available foodstuffs and the measuring out of medication. These learning experiences all culminated in the increased retention of the knowledge and skills needed to provide home care for the child concerned [22]. Accordingly, caregivers displayed knowledge, understanding and self-efficacy, which are essential qualities required of a competent caregiver who can provide safe homecare for a child with heart disease [7] [30]-[33].

Equally important is the fact that the programme interventions had enabled family members to gain a new perception of the children's condition and the demands of care. Following the programme interventions, the caregivers were able to move out of the limbo of emotional and care vulnerability, and were able to construct self-directed solutions to mediate the effects of negative appraisals of the caring role. They were able to reorganise roles and set priorities to manage the demands of caring for the child at home, there by demonstrating a collective responsibility for the provision of home care to the sick child [31] [34]. If the programme were extended to more of families from a similar context, their situation might also improve. Indeed, as Beck and Wiencek-Kurek (2007) [35] state, instead of passing judgement on people because of their socioeconomic situation, it is more important to acknowledge that caregivers of children with heart disease from the rural areas in Namibia are individuals with potential, who are trying to cope with a difficult situation and they therefore need to be assisted in order for them to do the best they can.

The challenge now involves ensuring the sustainability of this programme. Participants were empowered and were therefore able to redefine the challenges, conceptualise them as manageable and develop inner strength and self-determination. They were able to identify and utilise the strengths within the family and at the community level in order to help them cope with the demands of caring, hence overcoming a sense of powerlessness [20] [21]. Figure 1 below displays the outcomes of the programme evaluation.

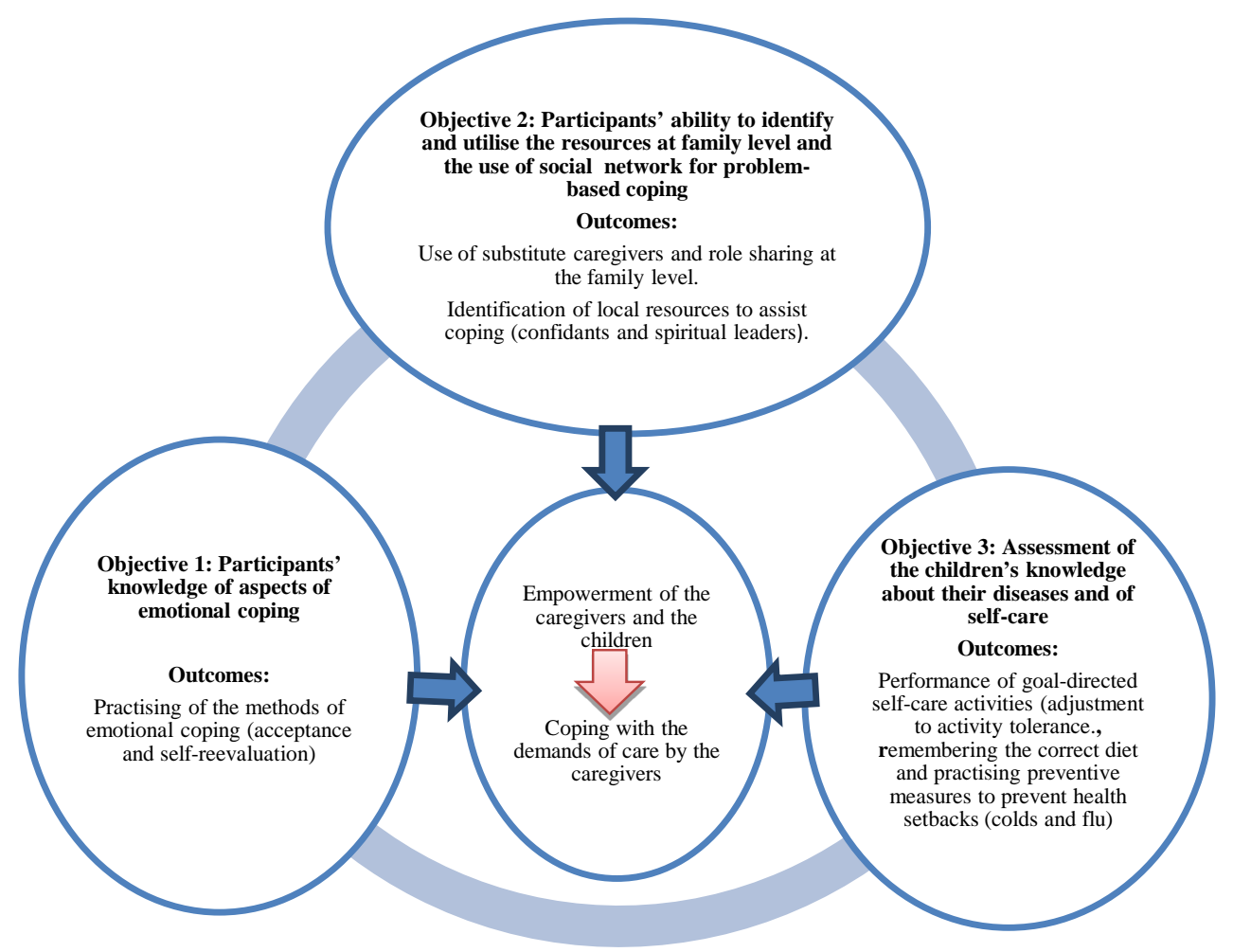

Figure 1. Outcomes of the programme evaluation. 


\section{Limitations}

The key limitation of the findings from the outcome evaluation of this support programme is inherent in the small sample size of the participants. It would therefore be the responsibility of interested organisations to determine independently the transferability of this study.

\section{Recommendations}

The positive findings from the implementation and evaluation of the support programme mean that the researcher is able to recommend that this programme be implemented at district level.

This programme could also be considered for inclusion in the palliative curriculum content for education of the prospect nurses at the local institutions.

\section{Acknowledgements}

The University of Namibia, Faculty of Health Science, School of Nursing and Public Health is gratefully acknowledged for all its facilitative contributions towards the completion of the study. Further, acknowledgement is accorded to the Namibian Ministry of Health and Social Services for the permission to conduct the study, the recommendations of which could contribute to the improvement of the quality of care for the clients of health services. Moreover, the rural caregivers and children with heart diseases are acknowledged for their participation in the study and the data they provided which are fundamental to the improvement of their situation at home.

\section{References}

[1] World Health Organization (WHO) (2009) Maternal and Child Health in Namibia. World Health Organization, Windhoek, Namibia.

[2] Coovadia, H.M. and Wittenberg, D.F. (2007) Paediatric and Child Health: A Manual for Health Professionals in Developing Countries. 5th Edition, Oxford University Press, Cape Town.

[3] Beck, C. and Wiencek-Kurek, J. (2007) Healthy Neighbourhood Heart Initiative: Bringing Community Health Theory to Civic Community. Cuyahonga Community, Cuyahonga. www.nc.maricopa.edu/other/engagement/Journal/Issue 3/Beck.pdf

[4] Amakali, K. (2013) Investigating the Need for a Home-Based Health Care Programme in Support of Parents/Caregivers of Children Diagnosed with Heart Disease in the Rural Areas of Namibia. Ph.D. Dissertation, University of Namibia, Namibia.

[5] Polit, D.F. and Beck, C.T. (2012) Nursing Research Generating and Assessing Evidence for Nursing Practice. 9th Edition, Lippincott Williams \& Wilkins, Philadelphia.

[6] Sandelowski, M. (2000) Focus on Research Method. Whatever Happened to Qualitative Research? Research in Nursing \& Health, 23, 334-340. http://dx.doi.org/10.1002/1098-240X(200008)23:4<334::AID-NUR9>3.0.CO;2-G

[7] Glanz, K., Rimer, B.K. and Viswanath, K. (2008) Health Behaviours and Health Education: Theory, Research and Practice. 4th Edition, Jossey-Bass, San Francisco.

[8] Dickoff, et al.’s (1968).

[9] Pretorius, S., Sliwa, K., Ruf, V., Walker, K. and Stewart, S. (2012) Feeding the Emergence of Advanced Heart Diseases in Soweto: A Nutritional Survey of Black African Patients with Heart Failure. Cardiovascular Journal of Africa (Official Journal for PASCAR), 23, 245-250. http://dx.doi.org/10.5830/CVJA-2011-021

[10] Wählin (2009).

[11] Boyse, K., Boujaode, L. and Laudray, J. (2011) Children with Chronic Conditions. University of Michigan, USA. http://www.med.unimich.edu/yourchild/topic/chronic.htm

[12] Parahoo, K. (2006) Nursing Research: Principle, Process and Issues. 6th Edition, Palgrave MacMillan, New York.

[13] Knowles, M. (2012) Informal Adult Education, Self-Direction and Andragogy. http://www.infed.org/thinkers/et-knwl.htm

[14] Pretorius, L. (2008) An Educational Programme to Facilitate Critical Thinking of Student Nurses in Namibia. Unpublished Ph.D. Thesis, University of Namibia, Windhoek.

[15] Meyer, M. (2004) Effective Facilitation: Practical Guidelines for Manager, Facilitators, Consultant and Trainers. New Africa Book, Claremont. 
[16] Nicolini, F. and Gherli, T. (2009) Alternative to Transplantation in the Surgical Therapy for Heart Failure. European Journal of Cardio-Thoracic Surgery, 35, 214-228. http://dx.doi.org/10.1016/j.ejcts.2008.11.003

[17] Gibson, T. (2007) Interventional Cardiology for Coronary Heart Disease. In: Oxford Handbook of Cardiac Nursing, Oxford University Press, Oxford.

[18] World Health Organization (WHO) (2002) Community Home-Based Care in Resource-Limited Settings: A Framework for Action. World Health Organization, Geneva.

[19] Chair, S.Y. and Pang, A.M.H. (2008) Patient Education before Undergoing Percutaneous Coronary Intervention. British Cardiac Nursing, 3, 32-36. http://dx.doi.org/10.12968/bjca.2008.3.1.27998

[20] Raina, P., O’Donnel, M., Rosenbaum, P., Brehaut, J., Walter, S.D., Russell, D., Swinton, M. and Wood, E. (2005) The Health and Well-Being of Caregivers of Children with Cerebral Palsy. Paediatrics, 115, e626-e636. http://dx.doi.org/10.1542/peds.2004-1689

[21] Mitchell, G.R. (2011) Empowering Caregivers. www.caregivers.com

[22] Cowley, S. (2004) Getting the Burger to Think. MPG Books, London.

[23] Maree, K. (2007) First Steps in Research. Van Schaik, Pretoria.

[24] Bugge, K.E., Helseth, S. and Darbyshire, P. (2009) Parents' Experiences of a Family Support Programme When a Parent Has Incurable Cancer. Journal of Clinical Nursing, 18, 3480-3488. http://dx.doi.org/10.1111/j.1365-2702.2009.02871.x

[25] Taylor-Powell, E., Steele, S. and Douglah, M. (1996) Planning a Programme Evaluation. University of Wisconsin. http://learningstore.uwex.edu/assets/pdf/g3658-pdf

[26] Tailor-Powell, Steele and Douglah.

[27] Creswell, J.W. (2008) Educational Research: Planning, Conducting and Evaluating Qualitative and Quantitative Research. 4th Edition, Pearson Education, New Jersey.

[28] Riegel, B., Vaughan Dickson, V., Goldberg, L.R. and Deatrick, J.A. (2007) Factors Associated with the Development of Expertise in Heart Failure Self-Care. Nursing Research, 56, 350-360.

[29] Thastrum, J.M., Munch-Hansen, A., Wiell, A. and Romer, G. (2006) Evaluation of a Short-Term Preventive Counselling Project for Families with a Patient with Cancer. Clinical Child Psychology and Psychiatry, 11, 529-542. http://dx.doi.org/10.1177/1359104506067875

[30] Ågren, S. (2010) Supportive Care for Patients with Heart Failure and Their Partners: A Descriptive and Interventional Study. Ph.D. Thesis, Division of Nursing Science, Department of Medical \& Health Sciences, Faculty of Health Sciences, Linkoping University, Sweden.

[31] George, J.B. (2008) Nursing Theories: The Base for Professional Nursing Practice. 4th Edition, Appleton \& Lange, Connecticut.

[32] Aljandro, P., Huberto, J. and Augustin, G.D. (2008) Reasoning and Knowledge by Cognitive Map: Pursuing a Holist Approach. Expert System Applications, 359, 2-18.

[33] Sniehotta, T.F., Scholz, U. and Schiwarzer, R. (2005) Bridging in the Intention-Behaviour Gap: Planning, Self-Efficacy and Action Control in the Adaptation and Maintenance of Physical Exercise. Psychology of Health, 20, 143-160. http://dx.doi.org/10.1080/08870440512331317670

[34] Stajduhar, K., Leigh Martin, W., Barwich, D. and Fyles, G. (2008) Factors Influencing Family Caregivers’ Ability to Cope with Providing End-of-Life Cancer Care at Home. Cancer Nursing, 31, 77-85. http://dx.doi.org/10.1097/01.NCC.0000305686.36637.b5

[35] Beck and Wiencek-Kurek (2007). 